\title{
ORIGINAL ARTICLE \\ Temporal stability in patterns of genetic diversity and structure of a marine foundation species (Zostera marina)
}

\author{
LK Reynolds ${ }^{1}$, JJ Stachowicz ${ }^{1}$, AR Hughes ${ }^{2}$, SJ Kamel ${ }^{3}$, BS Ort ${ }^{4}$ and RK Grosberg ${ }^{1}$ \\ Genetic diversity and population structure reflect complex interactions among a diverse set of processes that may vary \\ temporally, limiting their potential to predict ecological and evolutionary outcomes. Yet, the stability of these patterns is rarely \\ tested. We resampled eelgrass (Zostera marina) meadows from published studies to determine variability in genetic diversity and \\ structure within and between meadows over 5-12 years. The meadows sampled (San Francisco, Tomales and Bodega Bays in \\ California and the Virginia coastal bays) represent a range of life histories (annual vs perennial), age (well-established vs \\ restored) and environments (rural vs urbanized). In all of these systems, neither diversity nor differentiation $\left(F_{\mathrm{ST}}\right)$ changed over \\ time. Differences among tidal heights within Bodega Bay were also remarkably consistent, with the high intertidal being more \\ diverse than the subtidal, and tidal height differentiation being modest but significant at both time points. Historical studies \\ used only a few microsatellite loci; therefore, our temporal comparisons were based on 4-5 loci. However, analysis of the current \\ data using a set of 12 loci show that 4-5 loci are sufficient to describe diversity and differentiation patterns in this system. This \\ temporal consistency was not because of the resampling of large clones, underscoring the feasibility and relevance of \\ understanding drivers of the differences. Because seagrasses are declining at rapid rates, restoration and conservation are \\ increasingly a coastal management priority. Our results argue that surveys of eelgrass genetic structure and diversity at decadal \\ scales can provide accurate depictions of populations, increasing the utility of published genetic data for restoration and \\ designing networks of reserves. \\ Heredity (2017) 118, 404-412; doi:10.1038/hdy.2016.114; published online 28 December 2016
}

\section{INTRODUCTION}

The diversity and distribution of genetic variation within and among populations reflects the historical and contemporary interplay among a complex set of processes (reviewed in Hedgecock, 1986; Slatkin, 1987; Bohonak, 1999; Olsen et al., 2004; Bradbury et al., 2008; Selkoe and Toonen, 2011; Dawson et al., 2014). This information is often used to infer patterns of demographic connectivity, the potential for local adaptation and effective population size (Procaccini et al., 2007; Warren et al., 2014). These patterns also have important ecological implications at the community and ecosystem levels (Whitham et al., 2006; Hughes et al., 2008). Genetically diverse populations are often more stable and productive, and for habitat-forming species this results in increased habitat volume or complexity, and richer or more abundant associated communities (Hughes and Stachowicz, 2004, 2011; Reusch et al., 2005; Crutsinger et al., 2006; Johnson et al., 2006; Vellend 2006; Hughes et al., 2008). This mechanistic link has led to the use of spatial patterns of genetic diversity to infer spatial variation in functioning (see, for example, Hughes and Stachowicz, 2009; Duffy et al., 2015; Pohjanmies et al., 2015), but this application critically depends on the assumption that patterns of genetic diversity are stable over time.

Temporal variability in both genetic diversity and structure can be generated by temporal variation in a number of factors and processes including habitat characteristics, biotic interaction strength, early life-history, mortality or propagule transport pathways (for example, winds, current, waves). Larger perturbations, such as those that alter connectivity (for example, dams, current reversals) or increase recruitment (for example, masting years) considerably alter realized dispersal and connectivity among populations that, in turn, can affect population genetic structure (Yamamoto et al., 2004). Reductions in population size or local extinctions and subsequent recolonization alter patterns of genetic structure (Lessios et al., 1994; Diaz-Almela et al., 2007). More subtle changes can occur through genetic drift in isolated populations, such as captive salmon in hatcheries (Waples and Teel, 1990), although these effects may be negligible in larger interbreeding populations (Heath et al., 2002).

Few studies in either terrestrial or marine systems directly evaluate whether patterns of genetic variation and structure are consistent through time, and thus whether estimates of population history, connectivity and the ecological significance of these patterns are reliable (reviewed in Toonen and Grosberg, 2011). In this study, we assess the temporal stability of spatial patterns of allelic richness, clonal richness and relatedness and genetic structure in a widespread marine angiosperm, the eelgrass Zostera marina. Like all seagrasses, Z. marina is a clonal plant that can also reproduce sexually (Kendrick et al., 2012). Rhizome elongation contributes to local spread of genets (average rhizome elongation $26 \mathrm{~cm}$ per year). Sexual reproduction via seeds can contribute to local recruitment of new genets, as well as

${ }^{1}$ Department of Evolution and Ecology, University of California, Davis, Davis, CA, USA; ${ }^{2}$ Marine Science Center, Northeastern University, Nahant, MA, USA; ${ }^{3}$ Department of Biology and Marine Biology, University of North Carolina Wilmington, Wilmington, NC, USA and ${ }^{4}$ Olofson Environmental, Inc., Oakland, CA, USA

Correspondence: LK Reynolds, Department of Evolution and Ecology, University of California, Davis, 1 Shields Avenue Davis, CA 95616, USA.

E-mail: Ikreynolds@ucdavis.edu

Received 3 March 2016; revised 15 August 2016; accepted 18 September 2016; published online 28 December 2016 
longer distance dispersal via sediment waves (effective distance of meters), rafting of seeds at the surface via air bubbles (effective distance of hundreds of meters) and rafting of flowering shoots (effective distance of hundreds of km; Churchill et al., 1985; Harwell and Orth, 2002; Källström et al., 2008; Kendrick et al., 2012; Hosokawa et al., 2015). The contributions of clonal spread and sexual recruitment to the genetic composition of a population can vary with time and environmental conditions (Van Lent and Verschuure, 1994; Jarvis et al., 2012), such that meadows can vary from having an almost annual life history with obligate sexual reproduction due to regular disturbance (Jarvis et al., 2012) to almost exclusively vegetative spread and domination by a few very large clones (Reusch et al., 1999a). Similarly, allelic richness (using a set of microsatellite loci similar to the ones used here) varies from $\sim 1.2$ in the Baltic Sea to 6.4 in the east Pacific (Bodega Bay; Olsen et al., 2004). Significant differences in eelgrass genetic diversity and structure are also evident over much smaller spatial scales, such as across tidal heights and between adjacent bays (Ruckelshaus, 1998; Oetjen and Reusch, 2007a; Kamel et al., 2012). We do not know how persistent these larger- or smaller-scale patterns of diversity are over time; however, we do know that they have important ecological consequences (Hughes and Stachowicz, 2004, 2011; Reusch et al., 2005; Reynolds et al., 2012a). Our ability to use these patterns as indices of eelgrass ecosystem functioning or as predictors of population differentiation depends on the consistency of patterns over time.

Here we assess the stability of patterns of genetic diversity and structure within and among eelgrass meadows that vary in their age, their dominant life history and the intensity of local human influences (that is, urban vs rural environments). The gap between surveys ranges from 5 to 12 years, allowing for multiple recruitment events (Olesen and Sand-Jenson, 1994). We resurveyed eelgrass populations previously sampled in the mid-2000s in three separate bays, replicating the methods used by three different studies of these bays. Plots were not permanently marked. Resampled locations were instead as close as possible to the original sites. Therefore, our data reflect the consistency of spatial patterns among sites, but cannot reveal patterns of turnover at the level of individual genotypes at a particular site.

\section{MATERIALS AND METHODS}

\section{Study regions and general approach}

To characterize consistency in spatial and temporal patterns of genetic structure and diversity, we resampled $Z$. marina meadows from three different regions with previously published data on genetic structure: Bodega and Tomales Bays (Kamel et al., 2012), San Francisco Bay (Ort et al., 2012) and the Virginia coastal bays (Reynolds et al., 2012b). These bays differ in their geography, human impacts, dominant plant life history and genetic diversity. San Francisco, Bodega and Tomales Bays are all located in California on the Pacific coast of the United States, whereas the Virginia coastal bays are at a similar latitude on the Atlantic coast. San Francisco Bay is a highly urbanized estuary; Tomales, Bodega and the Virginia coastal bays have watersheds that are more rural suggesting different potential environmental drivers of diversity (Supplementary Figure S1).

Previous studies of $Z$. marina populations in Bodega Bay ranked them among the most diverse in terms of genotypic and allelic diversity in a specieswide survey (Olsen et al., 2004). Since then, Tomales Bay (Kamel et al., 2012) and the Virginia coastal bays (Reynolds et al., 2012b) have been shown to have similarly high diversity. In contrast, San Francisco Bay has significantly lower allelic diversity (Ort et al., 2012). Our San Francisco Bay sites include a semiannual meadow (Crown Beach) that dies back every winter and regenerates from seeds; all other meadows are perennial. Meadows in San Francisco, Tomales and Bodega Bays have persisted naturally over time; the meadows in the Virginia coastal bays are relatively young ( $<12$ years old) and were reestablished using seed from nearby Chesapeake Bay (McGlathery et al.,
2012; Orth et al., 2012). Because the goal of sampling these three regions was to compare changes over time within each region, we designed the resampling to match the previously published studies as closely as possible (Supplementary Figure S1). Consequently, sampling schemes (haphazard collection vs quadrat sampling) differed between regions. We highlight key details of the sampling schemes for each site here, but for more detail see the original studies.

\section{Bodega Bay and Tomales Bay (BB-TB)}

In October-November 2013, at two meadows (sites) in Bodega Bay (Westside Park (WP) and Channel Marker (CM)), two meadows in eastern Tomales Bay (Blake's Landing (BL) and Cypress Grove (CG)) and two meadows in western Tomales Bay (Sacramento Landing (SL) and Marshall Beach (MB)), we established four $1 \mathrm{~m} \times 1 \mathrm{~m}$ plots in the high intertidal $(<0 \mathrm{~m}$ mean lower low water (MLLW) ) and four $1 \mathrm{~m} \times 1 \mathrm{~m}$ plots in the subtidal $(\sim 0.7 \mathrm{~m}$ below MLLW). Within each plot, we randomly selected 25 shoots and sampled a $2 \mathrm{~cm}$ leaf segment from each shoot. We stored leaf segments at $-80^{\circ} \mathrm{C}$ before DNA extraction. We amplified 12 previously characterized microsatellite loci (CT12, CT19 (Reusch, 2000), CT3, GA2, GA3 (Reusch et al., 1999b), CL32 Contig 2, ZMC 12075, ZMC 13053, ZMC 19017 (Oetjen and Reusch, 2007b), CL 559 Contig 1, CL172 Contig 1, ZMC 19062 (Oetjen et al., 2010)). We analyzed fragments on an ABI 3010XL at the University of California Davis (Davis, CA, USA) DNA sequencing facility, and visualized the fragments using STRand software (Toonen and Hughes, 2001).

Using only samples where all loci successfully amplified, we identified genetically unique individuals by estimating $P_{\text {sex }}$, the probability that replicates of a clonal lineage were derived from separate sexual events, with the software GENCLONE 2.0 (Arnaud-Haond and Belkhir, 2007). Samples with a $P_{\text {sex }}<0.01$ were considered clonemates (Arnaud-Haond et al., 2007), with scoring errors and somatic mutations accounted for using the methods in Arnaud-Haond and Belkhir (2007) and Arnaud-Haond et al. (2007). We calculated genotypic richness $(R)$ as $(G-1) /(N-1)$ where $G$ is the number of clonal lineages in the population and $N$ is the number of samples.

Using only unique genets, we calculated allelic richness of each meadow and each tidal height, standardized to the smallest population size by rarefaction (smallest tidal height population $=13$, smallest meadow population 25) using FSTAT 2.9.3.2 (Goudet, 1995). We calculated average number of alleles per locus $(A)$, and mean expected heterozygosity $\left(H_{\mathrm{e}}\right)$ using GenAlEx 6.5 (Peakall and Smouse, 2012), and estimated $F_{\text {IS }}$ and tested for conformation to HardyWeinberg expectations using GenoDive 6.4 (Merimans and Van Tienderen, 2004).

Genetic diversity, population structure, and degree of relatedness were analyzed for (1) regions (Bodega Bay, eastern Tomales Bay and western Tomales Bay), (2) sites within regions (3) and tidal heights within sites. At each of these spatial scales, we calculated Weir and Cockerham's $F_{\mathrm{ST}}$ (10 000 permutations) using ARELQUIN v. 3.11 (Excoffier et al., 2005), Jost $D_{\mathrm{EST}}$ using GenoDive 6.4 (Merimans and Van Tienderen, 2004) and the dissimilarity index $(D)$ describing difference in allele length (Manhattan distance) described by Rozenfeld et al. (2007) using using GenoDive 6.4 (Merimans and Van Tienderen, 2004). We estimated average within group genetic relatedness (all vs all) ( $r$ ) among individuals within a sample using STORM (Frasier, 2008).

To analyze changes in diversity and structure over time, we used a subset of the genetic data (loci: CT12, CT19, CT3, GA2 and GA3) to compare with a similar survey conducted in 2001-2002 (Hughes and Stachowicz, 2009; Kamel et al., 2012). To verify consistent microsatellite scoring between sampling efforts, we reanalyzed (extraction, PCR, sequencing and scoring) a set of samples ( $N=8$ genotypes) that were scored in the earlier survey (Kamel et al., 2012); we found no differences in scoring of the same individuals between time points. We analyzed differences in diversity (clonal, allelic and heterozygosity) between the 2001 and 2013 surveys using a paired $t$-test (paired by meadow and by tidal height within meadow, to account for known effects of site and tidal elevation on genetic diversity; Kamel et al., 2012). Using both data sets, we quantified population differentiation using $F_{\mathrm{ST}}, D_{\mathrm{EST}}$ and Manhattan distance calculated as above. At each of the spatial scales described above, we also used Bayesian clustering methods, implemented in the software STRUCTURE v. 2.2.3 (Pritchard et al., 2000), to detect cryptic patterns of structure. The number of genetic clusters per region $(K)$ was determined using the $\Delta K$ method 
described by Evanno et al. (2005). To partition genetic variance within and among spatial scales, we used a hierarchical analysis of molecular variance (AMOVA) implemented in the software package ARELQUIN v. 3.11 (Excoffier et al., 2005).

Only five loci were shared between the contemporary and historical samples. We explored whether that subset of five loci gave a sufficiently accurate picture of genetic composition by comparing estimates of genotypic and allelic diversity calculated using those five loci, as well as the full set of 12 loci, using a paired $t$-test.

\section{San Francisco Bay (SFB)}

In October-November 2013, we sampled two sites in SFB (Crown Beach (CB) and Keller Beach (KB)) following protocols from a survey in 2006 (Ort et al., 2012). At each site, we removed a $2 \mathrm{~cm}$ leaf segment from 50 haphazardly chosen shoots, each separated by at least $10 \mathrm{~m}$. These leaf segments were stored at $-80^{\circ} \mathrm{C}$ and genotyped at the 12 polymorphic microsatellite loci described above. We estimated clonal identity and metrics of genetic diversity (allelic richness, number of alleles per locus, heterozygosity and inbreeding) and tested for confirmation to Hardy-Weinberg expectations as described above. We only included data from the subset of four loci used in the earlier survey (CT12, CT19, CT3 and GA3) to assess changes since 2006.

We used the BB-TB and SFB regions to characterize how large-scale spatial patterns and genetic differentiation on the meadow scale change over time and with a reduction in number of loci. We omitted the Virginia Coastal Bay region from this analysis because distance (and a continent) precludes substantial contemporary genetic exchange with the other regions. We used the four markers common to all analyses (CT12, CT19, CT3 and GA3) to compute pairwise $F_{\mathrm{ST}}, D_{\mathrm{EST}}$ and Manhattan distance values for each of the meadows (eight meadows total) at each time period. We regressed the current values against the historical values to assess whether patterns of differentiation were consistent over time. We also compared present-day pairwise $F_{\mathrm{ST}}$ values among all meadows using the four markers from earlier surveys and the total set of 12 markers to assess whether changes in the number of loci appreciably affected our estimates of contemporary genetic structure. Finally, we examined cryptic patterns of structure using Baysian modeling implemented in the software STRUCTURE v. 2.2.3 (Pritchard et al., 2000) as described above.

\section{Virginia Coastal Bays (VCB)}

In July 2013, at a single meadow in the VCB (South Bay (SB)), we haphazardly collected 50 samples that we stored on silica gel and analyzed at eight microsatellite loci (loci: CT3, GA2, GA3 (Reusch et al., 1999b), CT17H, CT35, CT19 and CT20 (Reusch, 2000)) using the methods described by Reynolds et al. (2012b). As for other sites, we calculated genetic diversity indices and changes in structure over time by comparing our data with data collected in 2008 (Reynolds et al., 2012b).

\section{RESULTS}

Across three regions, each with distinct sampling schemes, we found little evidence of temporal change in clonal diversity or allelic richness (Figure 1). Population differentiation between all bays remained consistent over time (Figure 2 and Supplementary Table S1), and even small differences between tidal heights within sites (that is, higher clonal richness in the intertidal vs the subtidal in Bodega Bay observed by Kamel et al., 2012) remained consistent across the two sampling points (Figure 3). Spatial patterns and estimates of genotypic and allelic diversity were robust to a reduction in the number of loci analyzed (Figures $2 \mathrm{~b}$ and 4 ).

\section{Bodega Bay and Tomales Bay}

We identified 244 unique genotypes from the 1152 tissue samples (using 12 loci, all unique genotypes had a $P_{\text {sex }}<0.01$ ). Some loci departed from Hardy-Weinberg equilibrium expectations (19/144 tests); however, no locus deviated in all populations, and no population deviated. The observed spatial patterns were similar to patterns found in samples from 12 years earlier (Kamel et al., 2012). Allelic diversity (mean number of alleles $\left(N_{\mathrm{A}}\right)=4.2$; mean allelic
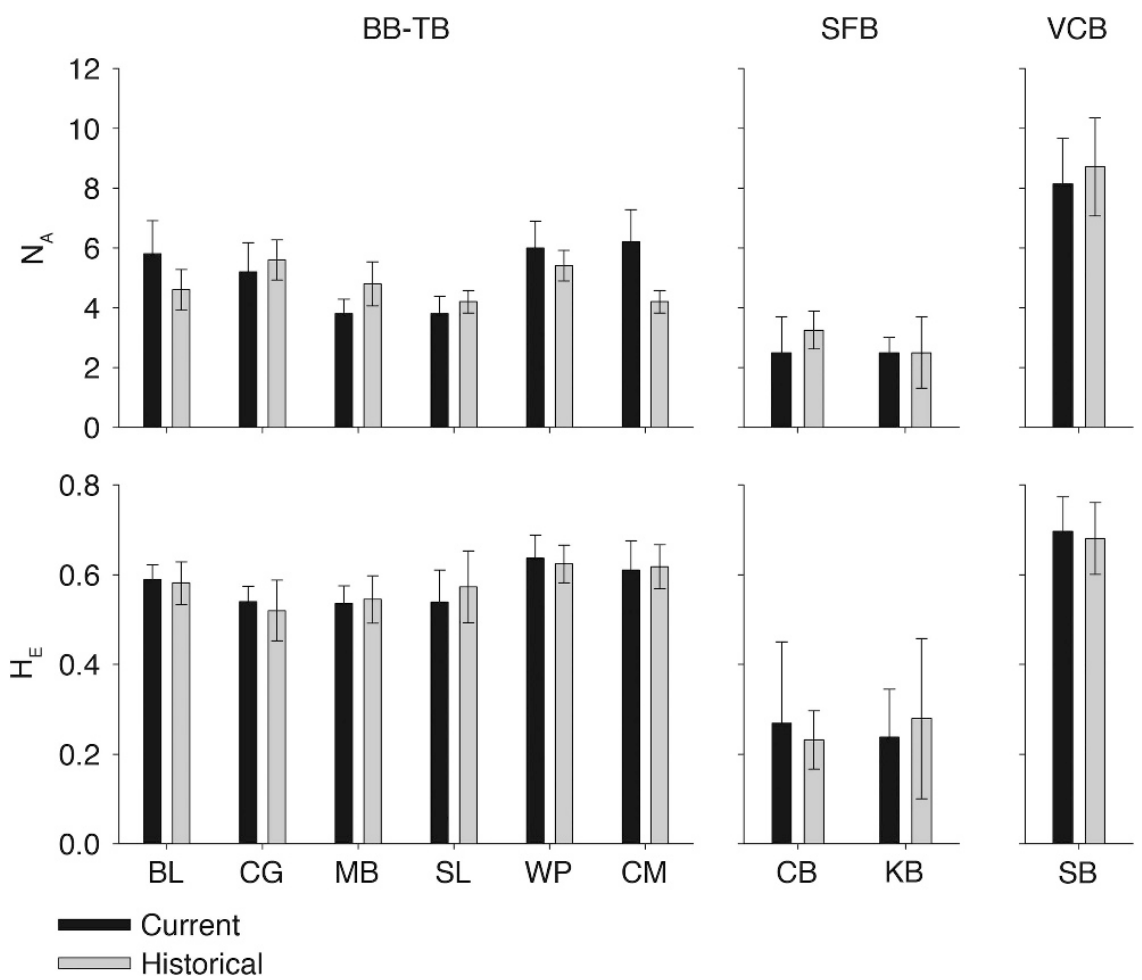

Figure 1 Z. marina genetic diversity ( allelic richness and expected heterozygosity; mean \pm 1 s.e.) at two sampling periods showing few differences among times and consistent patterns among sites. For Bodega and Tomales Bay, sampling was conducted 12 years apart; for San Francisco, 7 years apart; and the Virginia sites were 6 years apart. 

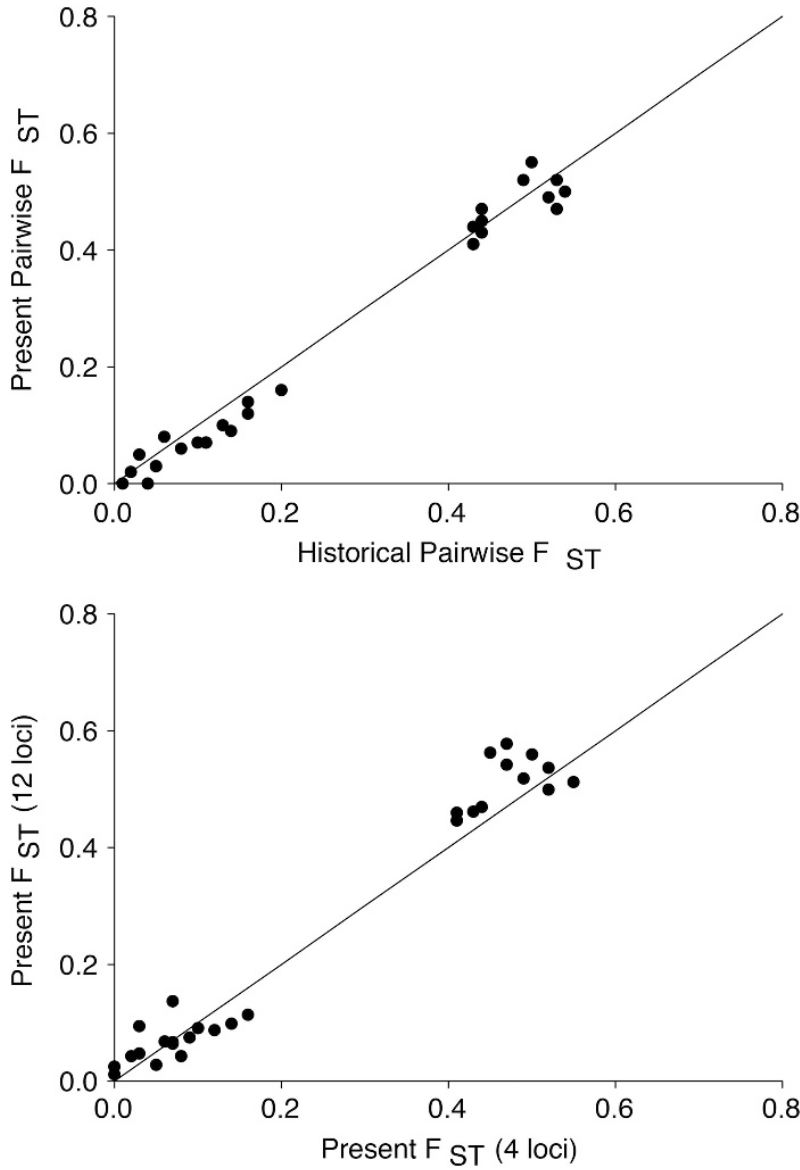

Figure 2 (Top) Z. marina population differentiation, estimated by $F_{\mathrm{ST}}$ (using 4 loci), between meadows in Bodega Bay, Tomales Bay and San Francisco Bay did not change between two sampling times 6 to 12 years apart. Historical samples are from Kamel et al. (2012) and Ort et al. (2012). The reference line is a 1:1 line. (Bottom) Population differentiation $\left(F_{\mathrm{ST}}\right)$ calculated with a full set of 12 loci vs the restricted set of 4 used in the study with the fewest markers. The reference line is a 1:1 line and indicates that for these loci and populations there is little change in $F_{\mathrm{ST}}$ with reduced number of markers.

richness $(\mathrm{AR})=3.84)$ and heterozygosity (mean $\left.H_{\mathrm{E}}=0.5\right)$ were uniformly high (Table 1). Genotypic diversity was also high (mean = 5.0 genotypes $\mathrm{m}^{-2}$, mean genotypic richness $(R)=0.2$ ); and there was a significant interaction (using analysis of variance) between region and tidal height, such that genotypic richness remained higher in the intertidal samples than in the subtidal samples in Bodega Bay $(F=7.00, P=0.05)$, but not in West Tomales $(F=1.00, P=0.5)$ or East Tomales Bay $(\mathrm{F}=0.76, P=0.5$; Figure 3$)$. The relatedness of individuals was higher on average in Tomales Bay than in Bodega Bay $(\mathrm{F}=7.61, P=0.01$ ), but did not differ between tidal heights (Figure 3 and Supplementary Table S2).

Across all analyses, spatial patterns of population differentiation were consistent, with little or no difference among temporal samples (Supplementary Table S1). AMOVA revealed that variation among tidal heights, sites and regions was comparable to the patterns in the 2001 samples (Kamel et al., 2012). No significant variation could be attributed to sampling year (Table 2). Allelic frequencies were similar between samplings (Supplementary Figure S2). Bayesian clustering implemented in the program STRUCTURE (Pritchard et al., 2000) supported differences between regions, but not differences over time
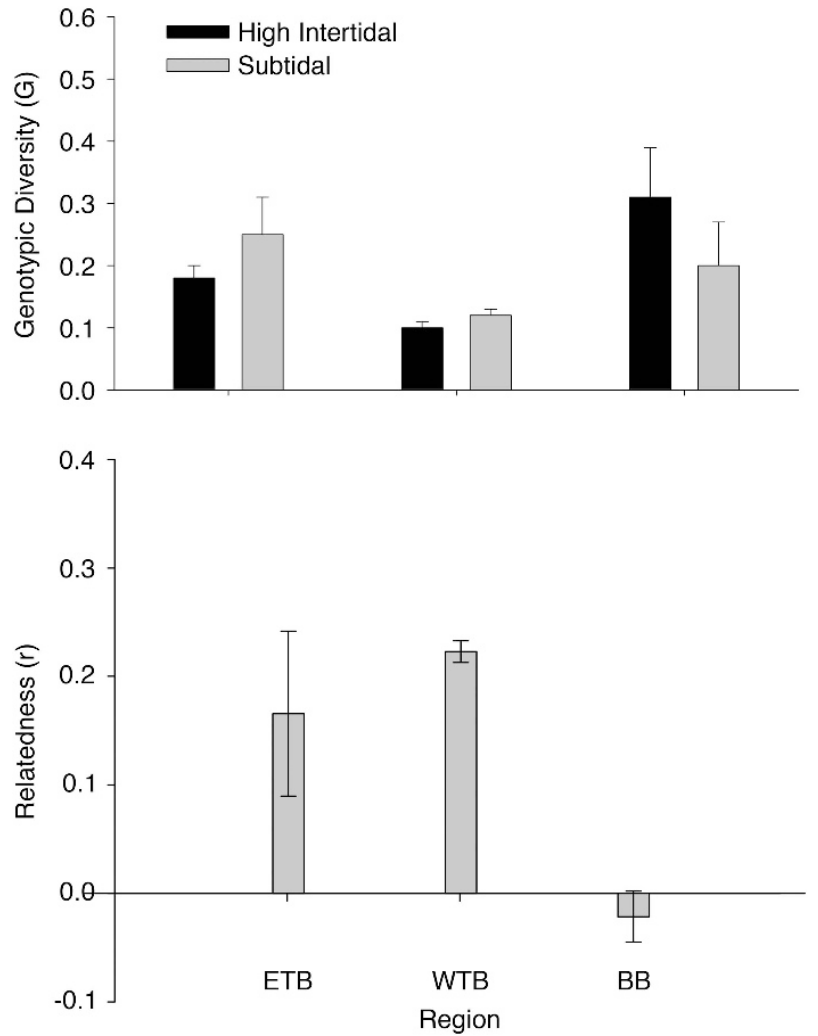

Figure 3 (Top) Consistent patterns of genotypic richness of Z. marina (mean +1 s.e.) across tidal elevations in Bodega Bay, West Tomales Bay and East Tomales Bay. High intertidal represents a depth of $\sim 0 \mathrm{~m} \mathrm{MLLW}$, and subtidal represents a depth of $\sim 0.7 \mathrm{~m} \mathrm{MLLW}$. The high intertidal and subtidal sites were separated by $<100 \mathrm{~m}$. (Bottom) Mean (+1 s.e.) genetic relatedness among genets within a plot, averaged across tidal heights within a site.

(Supplementary Figure S3). Paired $t$-tests comparing genotypic richness $(\mathrm{F}=1.0, P=0.3)$, allelic diversity $(\mathrm{F}=1.0, P=0.3)$ and expected heterozygosity $(\mathrm{F}=0.3, P=0.6)$ of meadows revealed no differences between sampling years (Figure 1). For each region there was a small but significant change in frequencies of some alleles (Supplementary Figure S2), but these did not alter patterns of genetic structure (Figure 2b). This consistency was not because of repeated sampling of long-lived clones. Of the 154 genets sampled in Bodega Bay in 2013, only 3 were present in the 2001 sample.

In our contemporary survey, most metrics differed by very small amounts when calculated with the full set of 12 loci vs the reduced set of 5 loci used in the 2001 survey. When calculated with 12 loci as opposed to 5 loci, there was no change in relatedness $(t=1.1, P=0.3)$, slightly increased genotypic richness $(G: 5$ loci $=0.22$ vs 12 loci $=0.23$, $t=3.3, P=0.02)$, slightly reduced allelic diversity and richness $\left(N_{\mathrm{A}}: 5\right.$ loci $=5.1$ vs 12 loci $=4.3, t=3.67, P=0.01$; AR: 5 loci $=4.6$ vs 12 loci $=3.9, t=3.7, P=0.01)$ and slightly reduced expected heterozygosity (5 loci $=0.58$ vs 12 loci $=0.51, t=3.32, P=0.02$; Figure 4 ).

\section{San Francisco Bay}

Of the 77 samples that we collected from SFB, 76 were unique genotypes. The two meadows sampled from the SFB region both had lower allelic diversity and richness (mean $N_{\mathrm{A}}=2.4$; mean $\mathrm{AR}=2.3$ ) and heterozygosity (mean $H_{\mathrm{E}}=0.26$ ) than those from Tomales and Bodega Bays. Only one locus (CL 559 Contig 1) in the Crown Beach meadow deviated significantly from Hardy-Weinberg equilibrium. No 

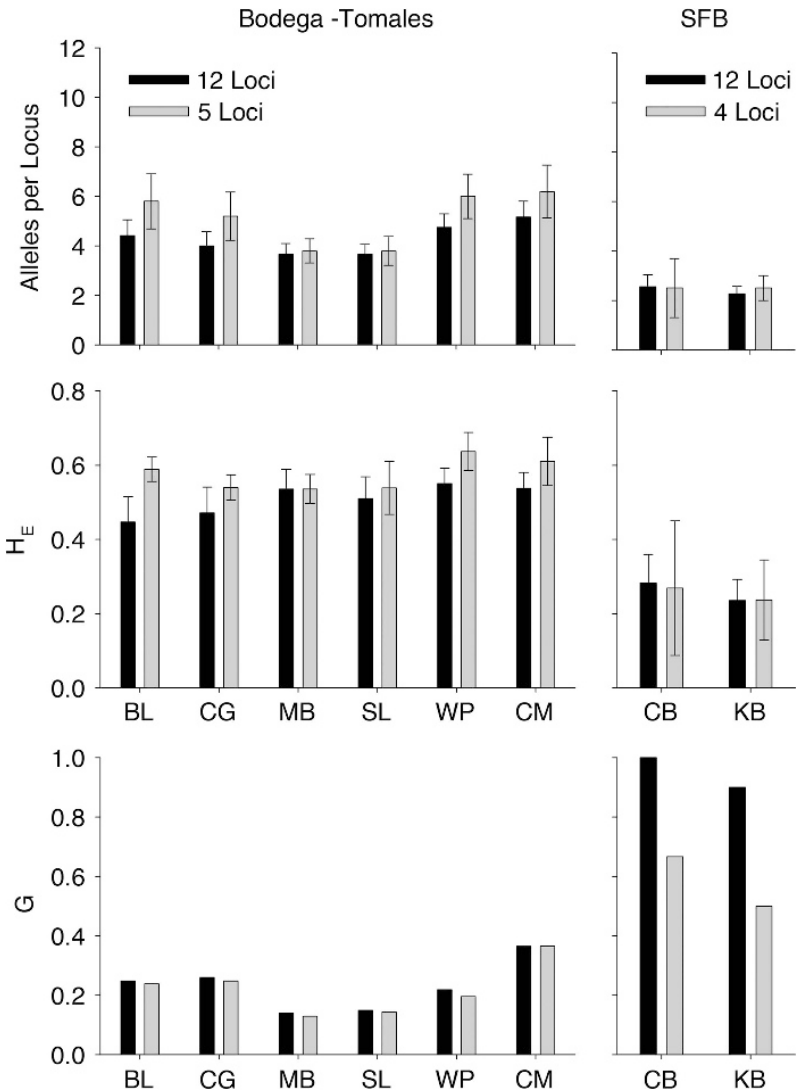

Figure 4 In order to compare samples with historical data with present samples, we used a reduced number of $Z$. marina microsatellite loci. Allelic and genotypic diversity calculated using both sets of markers are presented. See Materials and methods for loci.

population deviated from Hardy-Weinberg equilibrium. Because these samples were separated by at least $10 \mathrm{~m}$ to avoid collecting clonemates, clonal diversity was high (Crown Beach $G=1$, Keller Beach, $G=0.9$ ) but not directly comparable to the data from the other California bays, as our sampling scheme at each site conformed to the previous studies. Other California sites were sampled by collecting shoots within a single $\mathrm{m}^{2}$ quadrat. As in Bodega and Tomales Bays, allelic frequencies remained consistent over time (Supplementary Figure S4), and Bayesian clustering implemented in the program STRUCTURE (Pritchard et al., 2000) showed no differences over time (Supplementary Figure S5).

Diversity indices were robust to the number of loci analyzed. The SFB historical samples (from 2006) described by Ort et al. (2012) shared only four loci with our analyses; however, estimates of allelic diversity $\left(N_{\mathrm{A}}: t=0.67, P=0.6\right)$ and heterozygosity $\left(H_{\mathrm{E}}: t=0.87\right.$, $P=0.5)$ within meadows did not significantly change according to the number of loci used to generate the estimates (Figure 4). There was a nonsignificant reduction in clonal diversity when samples were analyzed at only four loci $(t=10.1, P=0.06)$, but the relative differences in clonal richness among sites were the same (Figure 2).

Based on the four shared loci, estimates of clonal diversity $(t=0.86$, $P=0.48)$, heterozygosity $(t=0.28, P=0.8)$ and allelic richness $(t=1.0$, $P=0.42)$ did not differ between samples taken in 2006 and 2013 (Figure 1). Spatial differentiation among SFB meadows estimated by $F_{\mathrm{ST}}$ and Bayesian clustering was greater than temporal differentiation (Supplementary Figures S4 and S5). Based on AMOVA, sampling year did not explain a significant amount of the total genetic variation
Table 1 Measures of Zostera marina diversity from each site

\begin{tabular}{|c|c|c|c|c|c|c|}
\hline Region & Site & Tide & $\mathrm{R}$ & $\mathrm{N}_{A}$ & $A R$ & $\mathrm{H}_{E}$ \\
\hline \multicolumn{7}{|l|}{$B B-T B$} \\
\hline \multirow[t]{6}{*}{ East Tomales Bay } & \multirow[t]{3}{*}{$\mathrm{BL}$} & $\mathrm{HI}$ & 0.23 & 3.83 & 3.35 & 0.43 \\
\hline & & S & 0.22 & 3.67 & 3.31 & 0.44 \\
\hline & & Total & 0.23 & 4.42 & 3.98 & 0.45 \\
\hline & \multirow[t]{3}{*}{$\mathrm{CG}$} & $\mathrm{HI}$ & 0.19 & 3.42 & 3.24 & 0.47 \\
\hline & & S & 0.32 & 3.50 & 3.05 & 0.46 \\
\hline & & Total & 0.26 & 4.00 & 3.61 & 0.47 \\
\hline \multirow[t]{6}{*}{ West Tomales Bay } & \multirow[t]{3}{*}{ MB } & $\mathrm{HI}$ & 0.12 & 3.08 & 3.08 & 0.48 \\
\hline & & S & 0.16 & 3.08 & 3.06 & 0.52 \\
\hline & & Total & 0.14 & 3.67 & 3.67 & 0.54 \\
\hline & \multirow[t]{3}{*}{$\mathrm{SL}$} & $\mathrm{HI}$ & 0.15 & 3.17 & 3.13 & 0.45 \\
\hline & & S & 0.14 & 3.42 & 3.45 & 0.53 \\
\hline & & Total & 0.15 & 3.67 & 3.72 & 0.51 \\
\hline \multirow[t]{6}{*}{ Bodega Bay } & \multirow[t]{3}{*}{ WP } & $\mathrm{HI}$ & 0.26 & 3.83 & 3.50 & 0.54 \\
\hline & & S & 0.17 & 3.83 & 3.63 & 0.53 \\
\hline & & Total & 0.22 & 4.75 & 4.34 & 0.55 \\
\hline & \multirow[t]{3}{*}{$\mathrm{CM}$} & $\mathrm{HI}$ & 0.41 & 4.42 & 3.68 & 0.52 \\
\hline & & S & 0.31 & 4.50 & 3.78 & 0.55 \\
\hline & & Total & 0.37 & 5.17 & 4.39 & 0.54 \\
\hline \multicolumn{7}{|l|}{$S F B$} \\
\hline & $\mathrm{CB}$ & & 1.00 & 2.55 & 2.41 & 0.28 \\
\hline & $\mathrm{KB}$ & & 0.93 & 2.27 & 2.25 & 0.24 \\
\hline \multicolumn{7}{|l|}{$V C B$} \\
\hline & SB & & 1.00 & 8.14 & 5.48 & 0.70 \\
\hline
\end{tabular}

Abbreviations: AR, allelic richness; BB-TB, Bodega Bay and Tomales Bay; BL, Blake's Landing; $\mathrm{CB}$, Crown Beach; CG, Cypress Grove; CM, Channel Marker; $H_{\mathrm{E}}$, expected heterozygosity; $\mathrm{HI}$, high intertidal; KB, Keller Beach; LI, low intertidal; MB, Marshall Beach; $N_{\mathrm{A}}$, number of alleles per locus; $R$, genotypic richness; S, subtidal; SB, South Bay; SFB, San Francisco Bay; SL, Sacramento Landing; VCB, Virginia Coastal Bays; WP, Westside Park.

(Table 2). In San Francisco Bay, 7 of the 66 multilocus genotypes sampled in 2013 were part of the historical data set; however, this likely reflects the reduced number and lower variability of markers used in the temporal analysis of those populations, rather than persistence and resampling of identical genets.

When we regressed historical pairwise $F_{\mathrm{ST}}$ values from all of the California sites against present-day values, the slope of the line was 1.0 $\left(R^{2}=0.98 ; P<0.0001\right.$; Figure 2$)$, indicating no change in population differentiation over the time between samples. Population differences described by $D_{\text {EST }}$ (slope $0.95, R^{2}=0.87 ; P<0.0001$ ) and Manhattan distances (slope $0.9, R^{2}=0.93 ; P<0.0001$ ) were very similar (Supplementary Figure S8). Estimates of population differentiation based on 4 versus 12 loci were strongly correlated (Figure 2; slope = $1.0, R^{2}=0.96 P<0.0001$ ), suggesting that this lack of difference is not merely because of limited power to detect structure based on 4 loci. Bayesian clustering implemented in the program STRUCTURE (Pritchard et al., 2000) also supported differences between regions, but not differences over time (Figure 5).

\section{Virginia Coastal Bays}

In the VCB, samples were separated by $\geqslant 5 \mathrm{~m}$, and given the apparently small extent of individual clones, this led to an estimate of clonal diversity equal to 1 . No genets appeared in both the historical and present-day data sets. These samples had a high allelic diversity and richness (mean $N_{\mathrm{A}}=8.1$; mean $\mathrm{AR}=5.5$ ) and a high expected heterozygosity (mean $H_{\mathrm{E}}=0.7$ ). Sites did not differ across samples in 2008 vs 2013 in clonal (all values were 1.0) or allelic diversity (5.6 
Table 2 Hierarchical analysis of molecular variance (AMOVA) for Zostera marina in each region: (a) Bodega Bay and Tomales Bays (b) San Francisco Bay and (c) the Virginia Coastal bays

\begin{tabular}{|c|c|c|c|c|}
\hline Source of variation & d.f. & Variance components & Percentage of variation & $\mathrm{P}$ \\
\hline \multicolumn{5}{|l|}{ (a) Bodega Bay-Tomales Bay } \\
\hline Among sampling dates & 1 & 0.002 & 0.1 & 0.4 \\
\hline Sites within regions & 11 & 0.09 & 0.4 & $<0.0001$ \\
\hline Tidal heights within Sites & 12 & 0.05 & 3.1 & $<0.0001$ \\
\hline within tidal heights & 808 & 1.4 & 90.6 & \\
\hline Among sampling dates & 1 & -0.3 & -5.8 & 1 \\
\hline Sites within sampling dates & 2 & 0.06 & 9.9 & $<0.0001$ \\
\hline Within Sites & 160 & 0.6 & 95.9 & \\
\hline \multicolumn{5}{|l|}{ (c) Virginia Coastal Bays } \\
\hline Among sampling dates & 1 & 0.01 & 0.7 & 0.2 \\
\hline
\end{tabular}

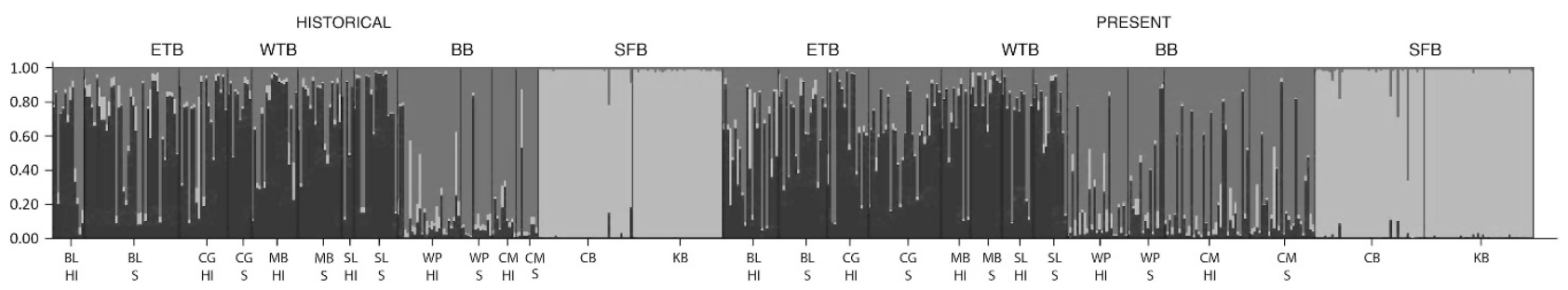

Figure 5 Z. marina Bayesian clustering using the program STRUCTURE from 4 =four regions (BB, Bodega Bay; ETB, East Tomales Bay; SFB, San Francisco Bay; and WTB, West Tomales Bay) at two sampling periods showing few differences among times and consistent patterns among sites. Each color represents a genetic cluster, and the number of clusters (3) was determined using the methods of Evanno et al. (2005).

(Reynolds et al., 2012b) vs 5.5 (Table 1), and estimates of population structure based on $F_{\mathrm{ST}}$ and Bayesian clustering remained constant between samples (Supplementary Table S1 and Supplementary Figure S7). Allelic frequencies were also consistent (Supplementary Figure S6). Similarly, AMOVA revealed no significant contribution of sampling year to the distribution of molecular variance (Table 2).

\section{DISCUSSION}

Temporal variation in allelic and genotypic richness, relatedness and among-population differentiation can occur at multiple spatial scales across a species distribution (Lessios et al., 1994; Becheler et al., 2014). However, we found no evidence for temporal variation in eelgrass genetic structure at any of the scales we investigated (regions, meadows and tidal heights) in three separate regions over sampling intervals of 5-12 years. This consistency occurred despite some modest changes in the frequencies of particular alleles, and a sampling time interval that exceeded the likely turnover time of individual ramets (Olesen and Sand-Jenson, 1994). Apparently, factors that determine and maintain eelgrass population genetic structure are consistent enough over multigenerational timescales that genetic snapshots are reliable indicators of consistent patterns of structure and diversity. To the extent that genetic structure and diversity are useful for inferring connectivity, population differentiation, resilience and ecosystem functioning, such genetic snapshots may also provide useful indicators of ecological status.
The consistency of genetic structure and diversity across scales implies that the forces that drive this structure persist over ecologically relevant time frames. For example, at the scale of different embayments (for example, Tomales Bay vs San Francisco Bay), the temporal stability in patterns of genetic differentiation (that is quite highSupplementary Table S1) likely reflects consistent, restricted dispersal over the $30 \mathrm{~km}$ of open water without stepping-stone habitats in between the two bays. The consistent patterns in diversity and relatedness between tidal heights within sites in Bodega Bay is not likely because of limits to dispersal, as they are only separated by $\sim 100 \mathrm{~m}$. Multiple mechanisms of dispersal, including rafting flowers (Harwell and Orth, 2002; Källström et al., 2008) and floating seeds (Tutin, 1938; Churchill et al., 1985), likely facilitate dispersal across these scales. Furthermore, meadows of this same species, separated by much larger distance $(\sim 50 \mathrm{~km})$ have shown almost no differentiation (Reusch, 2002). Instead, these persistent differences are probably driven by local ecological processes, such as higher rates of sexual reproduction combined with higher rates of disturbance (for example, air exposure, macroalgal blooms or geese grazing) at the upper intertidal edge of the beds that break up large clones, creating space for seedling recruitment (Kamel et al., 2012). Although we cannot yet determine the causes of these patterns, their consistency over time makes this a feasible and relevant endeavor.

Many of the processes known to cause temporal variation in genetic patterns in other systems (for example, disturbances, climate cycles) are known to be drivers in eelgrass dynamics (Collier et al., 2011; 
Thom et al., 2014). Nevertheless, the consistency that we observed within and among eelgrass meadows is widespread across regions that span the species variability in life histories and habitat quality. Notably, our samples included both annual (one SFB meadow) and perennial populations (BB-TB and VCB), as well as recently restored (VCB) and natural populations (BB-TB and $\mathrm{SFB}$ ). In addition, populations exhibiting this stability occurred in both human-impacted systems (SFB) and pristine systems with relatively low nutrient loading (VCB and $\mathrm{BB}$ ). Finally, we observed this stability in systems across a range of allelic diversity found in nature (see Olsen et al., 2004). However, all of the meadows we studied are relatively large, and all of the populations in this study contain small clones and high clonal diversity, presumably reflecting a predominance of sexual reproduction and recruitment (especially the annual meadow of Crown Beach in SFB and the meadow restored from seed in the VCB). Systems with large, persistent clones are not represented in our study. Multilocus genotypes were rarely resampled over time or over spaces bigger than the $1 \mathrm{~m}^{2}$ plots; therefore, stability in structure is not likely to be due simply to low turnover of individuals, as many of our sampled habitats (high intertidal, the annual SFB population) experience high turnover of individuals each year. Populations with longer lived individuals are expected to be very stable, with few changes even following disturbance events (Jahnke et al., 2015).

Some eelgrass beds are dominated by a few large, persistent clones (for example, some meadows in The Baltic Sea, The Black Sea, The Channel Islands and Puget Sound (Olsen et al., 2004)). These beds have limited recruitment and may be characterized by competitive exclusion; yet, these systems can also be quite stable. In one system with large clones that persist over time, Becheler et al. (2014) reported significant temporal (3-year) genetic structure within plots at same site and tidal elevation. They attributed this to increasing dominance of some clones within sites, as opposed to changes in population genetic diversity over time. Their analysis looked for temporal consistency in plots within a site that were initially very similar (little spatial structure), whereas ours examined temporal patterns over various spatial scales (from tidal heights to regions) where there was significant structure. When we reanalyzed the data from Becheler et al., (2014) at larger spatial scales (33 to $442 \mathrm{~km}$ ), however, patterns of genetic differentiation between sites are consistent over time, and at this scale, just like our study results, little variation is attributable to time relative to space (see Supplementary Information S2).

Differentiation and stability are important to our understanding of diversity-ecosystem function relationships. In eelgrass, among-site genetic differentiation within bays can predict trait differentiation (Abbott, 2015). Furthermore, both broad-scale surveys and small-scale experiments show that genetic diversity and eelgrass productivity, resilience and associated community diversity are positively related (Hughes and Stachowicz, 2004, 2009, 2011; Reusch et al., 2005; Stachowicz et al., 2013; Duffy et al., 2015). Given that both smallerand larger-scale patterns of genetic diversity persist over time, understanding the distribution of genetic diversity in nature may allow prediction of ecosystem functioning and resilience. This underscores the importance (and feasibility) of identifying the drivers of these differences in diversity.

The use of historical genetic data as a baseline for assessing temporal changes in genetic composition is often difficult as techniques evolve and older surveys may use markers that are now considered obsolete. For example, the diversity of eelgrass ( $Z$. marina) meadows in Chincoteague Bay revealed by allozyme markers in the 1990s was quite low (Williams and Orth, 1998), but using a similar sampling intensity and spatial scale, microsatellite markers subsequently revealed quite high diversity in 2012 (Reynolds et al., 2012b). Rather than a real temporal shift in diversity, this likely represents differences in resolution of the two types of genetic marker (see Reusch, 2001). Over the period of this study, microsatellites have been the dominant tool used to analyze genetic structure of seagrass populations, but the number of loci available has increased over time (for example, Hughes and Stachowicz, 2004 and Reusch et al., 2005 use 5 loci, whereas Reynolds et al., 2012b use 8 and Gonciarz et al., 2014 use 12 loci). By using nested subsets of loci in our analysis, we also assessed whether patterns of genetic structure are robust to changes in the number of loci in the analysis. Despite differences in the degree of statistical support for the robustness of measures of clonal diversity (in SFB samples), all spatial genetic patterns remained consistent whether we used only the 4-5 historical loci or the full 12-locus data set (Figures 2 and 4).

Because of the ecosystem services that seagrasses provide and their declining abundance (Costanza et al., 1997; Orth et al., 2006; Waycott et al., 2009), restoration and conservation of these plants is increasingly a priority for coastal management. The use of spatial distribution of genetic variation data within and among populations has been suggested as effective tools to direct conservation and restoration activities, yet genetic information is rarely used in seagrass management efforts (see Van Katwijk et al., 2009). For example, population genetic surveys could be used to identify priority conservation sites where genetic diversity and connectivity with other adjacent systems is high (Palumbi, 2003; Olsen et al., 2004; Procaccini et al., 2007). Similarly, population genetic surveys have been used to inform the collection of genetically diverse donor stock for restoration (Peterson et al., 2013). Alternatively, some restoration approaches choose locally adapted source populations for restoration (see Hufford and Mazer, 2003). The relative effectiveness of these strategies is unclear, and may vary among target species (Kettenring et al., 2014). Either strategy requires that the genetic landscape (distribution of diversity and relative migration between sites) is sufficiently stable over time to allow identification of source populations and patterns of connectivity. Our results argue that, at least in the absence of catastrophic disturbances, even decadal patterns of genetic structure and diversity can provide surprisingly accurate depictions of genetic patterns among eelgrass assemblages. This dramatically increases the potential utility of such genetic data for management actions such as restoration and designing networks of reserves.

\section{DATA ARCHIVING}

New data are archived and available at http://www.bco-dmo.org/ dataset/661446.

\section{CONFLICT OF INTEREST}

The authors declare no conflict of interest.

\section{ACKNOWLEDGEMENTS}

We thank Krista Viglienzoni for assistance in processing samples. This work was funded by NSF OCE 12-1234345 to JJS and RKG.

Abbott J (2015). Connecting genetic diversity to ecosystem functioning: the effects of genotypic richness, genetic relatedness, and trait variation in a seagrass community. PhD dissertation, University of California, Davis, Davis.

Arnaud-Haond S, Belkhir K (2007). GENCLONE: a computer program to analyse genotypic data, test for clonality and describe spatial clonal organization. Mol Ecol Notes 7: $15-17$.

Arnaud-Haond S, Duarte CM, Alberto F, Serrao EA (2007). Standardizing methods to address clonality in population studies. Mol Ecol 16: 5115-5139. 
Becheler R, Benkara E, Moalic Y, Hily C, Arnaud-Haond S (2014). Scaling of processes shaping the clonal dynamics and genetic mosaic of seagrasses through temporal genetic monitoring. Heredity 112: 114-121.

Bohonak AJ (1999). Dispersal, gene flow, and population structure. Q Rev Biol 74 21-45.

Bradbury IR, Laurel B, Snelgrove PVR, Bentzen P, Campana SE (2008). Global patterns in marine dispersal estimates: the influence of geography, taxonomic category and life history. Proc R Soc B Biol Sci 275: 1803-1809.

Churchill AC, Nieves G, Brenowitz AH (1985). Flotation and dispersal of eelgrass seeds by gas-bubbles. Estuaries 8: 352-354.

Collier CJ, Uthicke S, Waycott M. (2011). Thermal tolerance of two seagrass species at contrasting light levels: Implications for future distribution in the Great Barrier Reef Limnol Oceanogr 56: 2200-2210.

Costanza R, dArge R, deGroot R, Farber S, Grasso M, Hannon B et al. (1997). The value of the world's ecosystem services and natural capital. Nature 387: 253-260.

Crutsinger GM, Collins MD, Fordyce JA, Gompert Z, Nice CC, Sanders NJ (2006). Plant genotypic diversity predicts community structure and governs an ecosystem process. Science 313: 966-968.

Dawson MN, Hays CG, Grosberg RK, Raimondi PT (2014). Dispersal potential and population genetic structure in the marine intertidal of the eastern North Pacific. Ecol Monogr 84: 435-456.

Diaz-Almela E, Arnaud-Haond S, Vliet MS, Alvarez E, Marba N, Duarte CM et al. (2007). Feed-backs between genetic structure and perturbation-driven decline in seagrass (Posidonia oceanica) meadows. Conserv Genet 8: 1377-1391.

Duffy JE, Reynolds PL, Bostroem C, Coyer JA, Cusson M, Donadi S et al. (2015) Biodiversity mediates top-down control in eelgrass ecosystems: a global comparativeexperimental approach. Ecol Lett 18: 696-705.

Evanno G, Regnaut S, Goudet J (2005). Detecting the number of clusters of individuals using the software STRUCTURE: a simulation study. Mol Ecol 14: 2611-2620.

Excoffier L, Laval G, Schneider S (2005). Arlequin (version 3.0): An integrated software package for population genetics data analysis. Evol Bioinform 1: 47-50.

Frasier TR (2008). STORM: software for testing hypotheses of relatedness and mating patterns. Mol Ecol Resour 8: 1263-1266.

Gonciarz M, Wiktor J, Tatarek A, Weglenski P, Stankovic A (2014). Genetic characteristics of three Baltic Zostera marina populations. Oceanologia 56: 549-564.

Goudet J (1995). FSTAT (Version 1.2): A computer program to calculate F-statistics. Journal of Heredity 86: 485-486

Harwell MC, Orth RJ (2002). Long-distance dispersal potential in a marine macrophyte. Ecology 83: 3319-3330.

Heath DD, Busch C, Kelly J, Atagi DY (2002). Temporal change in genetic structure and effective population size in steelhead trout (Oncorhynchus mykiss). Mol Ecol 11 197-214.

Hedgecock D (1986). Is gene flow from pelagic larval dispersal important in the adaptation and evolution of marine invertebrates. Bull Mar Sci 39: 550-564.

Hosokawa S, Nakaoka M, Miyoshi E, Kuwae T (2015). Seed dispersal in the seagrass Zostera marina is mostly within the parent bed in a protected bay. Mar Ecol Prog Series 523: 41-56.

Hufford KM, Mazer SJ (2003). Plant ecotypes: genetic differentiation in the age of ecological restoration. Trends Ecol Evol 18: 147-155.

Hughes AR, Inouye BD, Johnson MTJ, Underwood N, Vellend M (2008). Ecological consequences of genetic diversity. Ecol Lett 11: 609-623.

Hughes AR, Stachowicz JJ (2004). Genetic diversity enhances the resistance of a seagrass ecosystem to disturbance. Proc Natl Acad Sci USA 101: 8998-9002.

Hughes AR, Stachowicz JJ (2009). Ecological impacts of genotypic diversity in the clonal seagrass Zostera marina. Ecology 90: 1412-1419.

Hughes AR, Stachowicz JJ (2011). Seagrass genotypic diversity increases disturbance response via complementarity and dominance. J Ecol 99: 445-453.

Jahnke M, Olsen JL, Procaccini G (2015). A meta-analysis reveals a positive correlation between genetic diversity metrics and environmental status in the long-lived seagrass Posidonia oceanica. Mol Ecol 24: 2336-2348.

Jarvis JC, Moore KA, Kenworthy WJ (2012). Characterization and ecological implication of eelgrass life history strategies near the species' southern limit in the western North Atlantic. Mar Ecol Prog Ser 444: 43-56.

Johnson MTJ, Lajeunesse MJ, Agrawal AA (2006). Additive and interactive effects of plant genotypic diversity on arthropod communities and plant fitness. Ecol Lett 9: 24-34.

Källström B, Nyqvist A, Aberg P, Bodin M, Andre C (2008). Seed rafting as a dispersa strategy for eelgrass (Zostera marina). Aquat Bot 88: 148-153.

Kamel SJ, Hughes AR, Grosberg RK, Stachowicz JJ (2012). Fine-scale genetic structure and relatedness in the eelgrass Zostera marina. Mar Ecol Prog Ser 447 127-164.

Kendrick GA, Waycott M, Carruthers TJB, Cambridge ML, Hovey R, Krauss SL et al. (2012). The central role of dispersal in the maintenance and persistence of seagrass populations. Bioscience 62: 56-65.

Kettenring KM, Mercer KL, Adams CR, Hines J (2014). Application of genetic diversityecosystem function research to ecological restoration. J Appl Ecol 51: 339-348.

Lessios HA, Weinberg JR, Starczak VR (1994). Temporal variation in the populations of the marine isopod Excirolana - how stable are gene frequencies and morphology. Evolution 48: 549-563.

McGlathery KJ, Reynolds LK, Cole LW, Orth RJ, Marion SR, Schwarzschild A (2012). Recovery trajectories during state change from bare sediment to eelgrass dominance. Mar Ecol Prog Ser 448: 209-221.

Merimans PG, Van Tienderen PH (2004). GENOTYPE and GENODIVE: two programs for the analysis of genetic diversity of asexual organisms. Mol Ecol Notes 4: 792-794.
Oetjen K, Ferber S, Dankert I, Reusch TBH (2010). New evidence for habitat-specific selection in Wadden Sea Zostera marina populations revealed by genome scanning using SNP and microsatellite markers. Mar Biol 157: 81-89.

Oetjen K, Reusch TBH (2007a). Genome scans detect consistent divergent selection among subtidal vs. intertidal populations of the marine angiosperm Zostera marina. $\mathrm{Mol}$ Ecol 16: 5156-5167.

Oetjen K, Reusch TBH (2007b). Identification and characterization of 14 polymorphic EST-derived microsatellites in eelgrass (Zostera marina). Mol Ecol Notes 7: 777-780.

Olesen B, Sand-Jenson K (1994). Demography of shallow eelgrass (Zostera marina) populations - shoot dynamics and biomass development. J Ecol 82: 379-390.

Olsen JL, Stam WT, Coyer JA, Reusch TBH, Billingham M, Bostrom C et al. (2004). North Atlantic phylogeography and large-scale population differentiation of the seagrass Zostera marina L. Mol Ecol 13: 1923-1941.

Ort BS, Cohen CS, Boyer KE, Wyllie-Echeverria S (2012). Population structure and genetic diversity among eelgrass (Zostera marina) beds and depths in San Francisco Bay. $J$ Hered 103: 533-546.

Orth RJ, Carruthers TJB, Dennison WC, Duarte CM, Fourqurean JW, Heck KL Jr et al. (2006). A global crisis for seagrass ecosystems. Bioscience 56: 987-996.

Orth RJ, Moore KA, Marion SR, Wilcox DJ, Parrish DB (2012). Seed addition facilitates eelgrass recovery in a coastal bay system. Mar Ecol Prog Ser 448: 177-195.

Palumbi SR (2003). Population genetics, demographic connectivity, and the design of marine reserves. Ecol App/ 13: S146-S158.

Peakall R, Smouse PE (2012). GENALEX 6: genetic analysis in Excel. Population genetic software for teaching and research. $\mathrm{Mol}$ Ecol Notes 6: 288-295.

Peterson BJ, Bricker E, Brisbin SJ, Furman BT, Stubler AD, Carroll JM et al. (2013). Genetic diversity and gene flow in Zostera marina populations surrounding Long Island, New York, USA: no evidence of inbreeding, genetic degradation or population isolation. Aquat Bot 110: 61-66.

Pohjanmies T, Tack AJM, Pulkkinen P, Elshibli S, Vakkari P, Roslin T (2015). Genetic diversity and connectivity shape herbivore load within an oak population at its range limit. Ecosphere 6: 101.

Pritchard JK, Stephens M, Donnelly P (2000). Inference of population structure using multilocus genotype data. Genetics 155: 945-959.

Procaccini G, Olsen JL, Reusch TBH (2007). Contribution of genetics and genomics to seagrass biology and conservation. J Exp Mar Biol Ecol 350: 234-259.

Reusch TBH (2000). Five microsatellite loci in eelgrass Zostera marina and a test of crossspecies amplification in Z. noltii and Z. japonica. Mol Ecol 9: 371-373.

Reusch TBH (2001). New markers - old questions: population genetics of seagrasses. Mar Ecol Prog Ser 211: 261-274.

Reusch TBH (2002). Microsatellites reveal high population connectivity in eelgrass (Zostera marina) in two contrasting coastal areas. Limnology and Oceanography 47: 7885.

Reusch TBH, Bostrom C, Stam WT, Olsen JL (1999a). An ancient eelgrass clone in the Baltic. Mar Ecol Prog Ser 183: 301-304

Reusch TBH, Ehlers A, Hammerli A, Worm B (2005). Ecosystem recovery after climatic extremes enhanced by genotypic diversity. Proc Natl Acad Sci USA 102: 2826-2831.

Reusch TBH, Stam WT, Olsen JL (1999b). Size and estimated age of genets in eelgrass, Zostera marina, assessed with microsatellite markers. Mar Biol 133: 519-525.

Reynolds LK, McGlathery KJ, Waycott M (2012a). Genetic diversity enhances restoration success by augmenting ecosystem services. PLoS One 7: e38397.

Reynolds LK, Waycott M, McGlathery KJ, Orth RJ, Zieman JC (2012b). Eelgrass restoration by seed maintains genetic diversity: case study from a coastal bay system. Mar Ecol Prog Ser 448: 223-233.

Rozenfeld AF, Arnaud-Haond S, Hernández-García E, Eguíluz VM, Matías MA, Serrao E et al. (2007). Spectrum of genetic diversity and networks of clonal organisms. J R Soc Interface 4: 1093-1102.

Ruckelshaus MH (1998). Spatial scale of genetic structure and an indirect estimate of gene flow in eelgrass, Zostera marina. Evolution 52: 330-343.

Selkoe KA, Toonen RJ (2011). Marine connectivity: a new look at pelagic larval duration and genetic metrics of dispersal. Mar Ecol Prog Ser 436: 291-305.

Slatkin M (1987). Gene flow and the geographic structure of natural populations. Science 236: 787-792.

Stachowicz JJ, Kamel SJ, Hughes AR, Grosberg RK (2013). Genetic relatedness influences plant biomass accumulation in eelgrass (Zostera marina). Am Nat 181: 715-724.

Thom R, Southard S, Borde A (2014). Climate-linked mechanisms driving spatial and temporal variation in eelgrass (Zostera marina L.) Growth and assemblage structure in Pacific Northwest estuaries, USA. J Coastal Res 68: 1-11.

Toonen RJ, Grosberg RK (2011). Causes of chaos: spatial and temporal genetic heterogeneity in the intertidal anomuran crab Petrolisthes cinctipes. In:Held C Koenemann S, Schubart CD (eds). Phylogeography and Population Genetics in Crustacea. CRC Press: Boca Raton FL., pp 75-107.

Toonen RJ, Hughes S (2001). Increased throughput for fragment analysis on an ABI PRISM (R) automated sequencer using a membrane comb and STRand software. Biotechniques 31: $1320-1324$

Tutin TG (1938). The autecology of Zostera marina in relation to its wasting disease. New Phytol 37: 50-71.

Van Katwijk MM, Bos AR, De Jonge VN, Hanssen LSAM, Hermus DCR, De Jong DJ (2009). Guidelines for seagrass restoration: importance of habitat selection and donor population, spreading of risks, and ecosystem engineering effects. Mar Poll Bull 58: 179-188.

Van Lent F, Verschuure JM (1994). Intraspecific variability of Zostera-marina L (eelgrass) in the estuaries and lagoons of the southwestern Netherlands. 2. Relation with environmental-factors. Aquat Bot 48: 59-75.

Vellend M (2006). The consequences of genetic diversity in competitive communities. Ecology 87: 304-311. 
Waples RS, Teel DJ (1990). Conservation genetics of pacific salmon. 1. Temporal changes in allele frequency. Conserv Biol 4: 144-156.

Warren IA, Ciborowski KL, Casadei E, Hazlerigg DG, Martin S, Jordan WC et al. (2014). Extensive local gene duplication and functional divergence among paralogs in Atlantic salmon. Genome Biol Evol 6: 1790-1805.

Waycott M, Duarte CM, Carruthers TJB, Orth RJ, Dennison WC, Olyarnik S et al. (2009). Accelerating loss of seagrasses across the globe threatens coastal ecosystems. Proc Natl Acad Sci USA 106: 12377-12381.
Whitham TG, Bailey JK, Schweitzer JA, Shuster SM, Bangert RK, LeRoy CJ et al. (2006). A framework for community and ecosystem genetics: from genes to ecosystems. Nat Rev Genet 7: 510-523.

Williams SL, Orth RJ (1998). Genetic diversity and structure of natural and transplanted eelgrass populations in the Chesapeake and Chincoteague bays. Estuaries 21: 118-128. Yamamoto S, Morita K, Koizumi I, Maekawa K (2004). Genetic differentiation of whitespotted charr (Salvelinus leucomaenis) populations after habitat fragmentation: spatialtemporal changes in gene frequencies. Conserv Genet 5: 529-538.

Supplementary Information accompanies this paper on Heredity website (http://www.nature.com/hdy) 